\title{
Gastric Antral Vascular Ectasia: Case Report and Review of the Literature
}

\author{
Papia Kar, MD; Subhashis Mitra, MD; Jeffrey M. Resnick, MD; and \\ Camille F. Torbey, MD, FACP, AGAF
}

\begin{abstract}
Gastric antral vascular ectasia is the source of up to $4 \%$ of nonvariceal upper gastrointestinal bleeding. It can present with occult bleeding requiring transfusions or with acute gastrointestinal bleeding. It is associated with significant morbidity and mortality and has been associated with such underlying chronic diseases as scleroderma, diabetes mellitus, and hypertension. Approximately $30 \%$ of cases are associated with cirrhosis. We report two cases of gastric antral vascular ectasia with two strikingly different endoscopic appearances. We further describe the clinical, endoscopic, histologic, and therapeutic aspects of this entity.
\end{abstract}

Keywords: Endoscopy; Gastric antral vascular ectasia; Gastrointestinal bleeding; GAVE

\footnotetext{
Corresponding Author:

Camille F. Torbey, MD, FACP, AGAF

Department of Gastroenterology

1000 North Oak Avenue

Marshfield, WI 54449

Tel: $7 \mid 5-221-7833$

Fax: 7I5-387-5663

Email: torbey.camille@marshfieldclinic.org

Received: July 18, 2011

Ist Revision: May 12, 2012

2nd Revision: October 5, 2012

Accepted: October 10, 2012

Published online ahead of print:

December 2I, 2012

doi: $10.3121 / \mathrm{cmr} .2012 .1036$
}

$\mathrm{G}$

astric antral vascular ectasia (GAVE) is a rare cause of upper gastrointestinal (GI) bleeding, accounting for $4 \%$ of nonvariceal upper GI bleeding and associated with occult bleeding that manifests as iron deficiency anemia. ${ }^{1}$ In recent years, it has emerged as a distinctive, well-defined entity within the spectrum of acquired vasculopathies of the stomach.

We report two cases of GAVE presenting with two different endoscopy findings. We discuss the etiology, endoscopic features, histology, pathogenesis, and management options of this rare entity, and present a review of the pertinent literature.

\section{Case I}

A man, age 57 years, presented with a one-week history of hematemesis. He described three episodes of coffee ground emesis, about a half-cupful on each occasion. The most recent episode occurred on the day of admission. His past medical history was significant for alcoholic cirrhosis with portal hypertension. $\mathrm{He}$ had an episode of hematochezia in the past that was diagnosed as a diverticular bleed on colonoscopy. His social history was significant for alcohol abuse, but he had quit drinking about 10 years prior.

His vital signs showed a temperature of $98.9^{\circ} \mathrm{F}$, pulse 102 beats/minute, respiratory rate 16 breaths/minute, and blood pressure 120/79 mm Hg. Physical examination revealed a pale, jaundiced, malnourished male with ascites, pedal edema, and bilateral basal crackles. Initial laboratory studies were significant for hemoglobin of $8.8 \mathrm{gm} / \mathrm{dL}$ (reference range 12.9-17.3 g/dL). Serum liver tests 


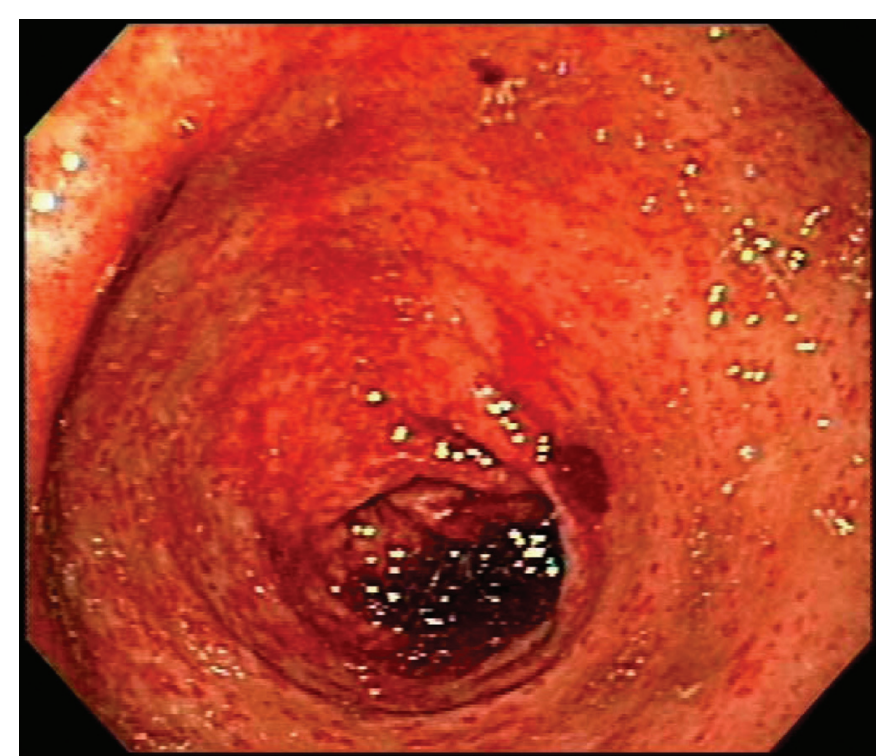

Figure 1. Endoscopy from case 1 showing diffuse punctate lesions in the antrum.

revealed total bilirubin of $1.9 \mathrm{mg} / \mathrm{dL}$ (reference range $0.4-1.4$ $\mathrm{mg} / \mathrm{dL}$ ), aspartate aminotransferase $48 \mathrm{U} / \mathrm{L}$ (reference range 15-46 U/L), alanine aminotransferase $22 \mathrm{U} / \mathrm{L}$ (reference range 10-61 U/L), and alkaline phosphatase $409 \mathrm{U} / \mathrm{L}$ (reference range $98-317 \mathrm{U} / \mathrm{L}$ ).

The patient received two units of packed red blood cell transfusion on admission. An esophagogastroduodenoscopy (EGD) showed diffuse punctate hemorrhage in the antrum, compatible with the punctate form of GAVE commonly encountered among cirrhotic patients, with signs of active bleeding (figure 1). There was no evidence of esophageal or gastric varices. The proximal portion of the stomach revealed changes consistent with portal hypertensive gastropathy, characterized by the so-called "mosaic" pattern of the gastric wall along with mucosal red spots, without active bleeding. The bleeding sites were successfully treated with argon plasma coagulation (APC). He was monitored closely and had no further episodes of bleeding. His hemoglobin remained stable before discharge. The patient was lost to follow-up at our facility.

\section{Case 2}

A Caucasian woman, age 68 years, was admitted with complaints of exertional dyspnea and orthopnea of 2 weeks duration. She denied any chest pain or palpitations. Past medical history was significant for coronary artery disease, morbid obesity, hypertension, and poorly controlled type 2 diabetes mellitus.

Her vital signs showed a temperature of $97.7^{\circ} \mathrm{F}$, pulse 90 beats/minute, respiratory rate 18 breaths/minute, and blood pressure 143/61 mm Hg. Physical examination revealed conjunctival pallor and bilateral basal crackles with leg edema. Rectal examination revealed hemoccult-positive stool. Laboratory studies revealed a hemoglobin level of $6.6 \mathrm{gm} / \mathrm{dL}$ (reference range 11.7-15.5 gm/dL) with a hematocrit of $21.7 \%$ (reference range $35-46 \%$ ). Platelet count was normal at $254 \times 10^{3} / \mu \mathrm{L}$. Iron studies revealed a serum iron level of $11 \mu \mathrm{g} / \mathrm{dL}$ (reference range $40-160 \mu \mathrm{g} / \mathrm{dL}$ ) with a total iron binding capacity of $570 \mu \mathrm{g} / \mathrm{dL}$ (reference range $260-420 \mu \mathrm{g} / \mathrm{dL})$.

The patient received four units of packed red cell transfusion, and her hematocrit was closely monitored. She underwent an EGD, which showed areas of hyperemic streaks alternating with normal-appearing mucosa in the antrum, consistent with "watermelon stomach" (figure 2A). A biopsy was obtained. The bleeding sites responded well to APC (figure 2B). The hemoglobin remained stable post-procedure. The gastric antral biopsy showed patchy fibromuscular proliferation of the lamina propria, accompanied by dilated/congested capillaries and fibrin thrombi; the histologic features were characteristic of GAVE (figure 3).
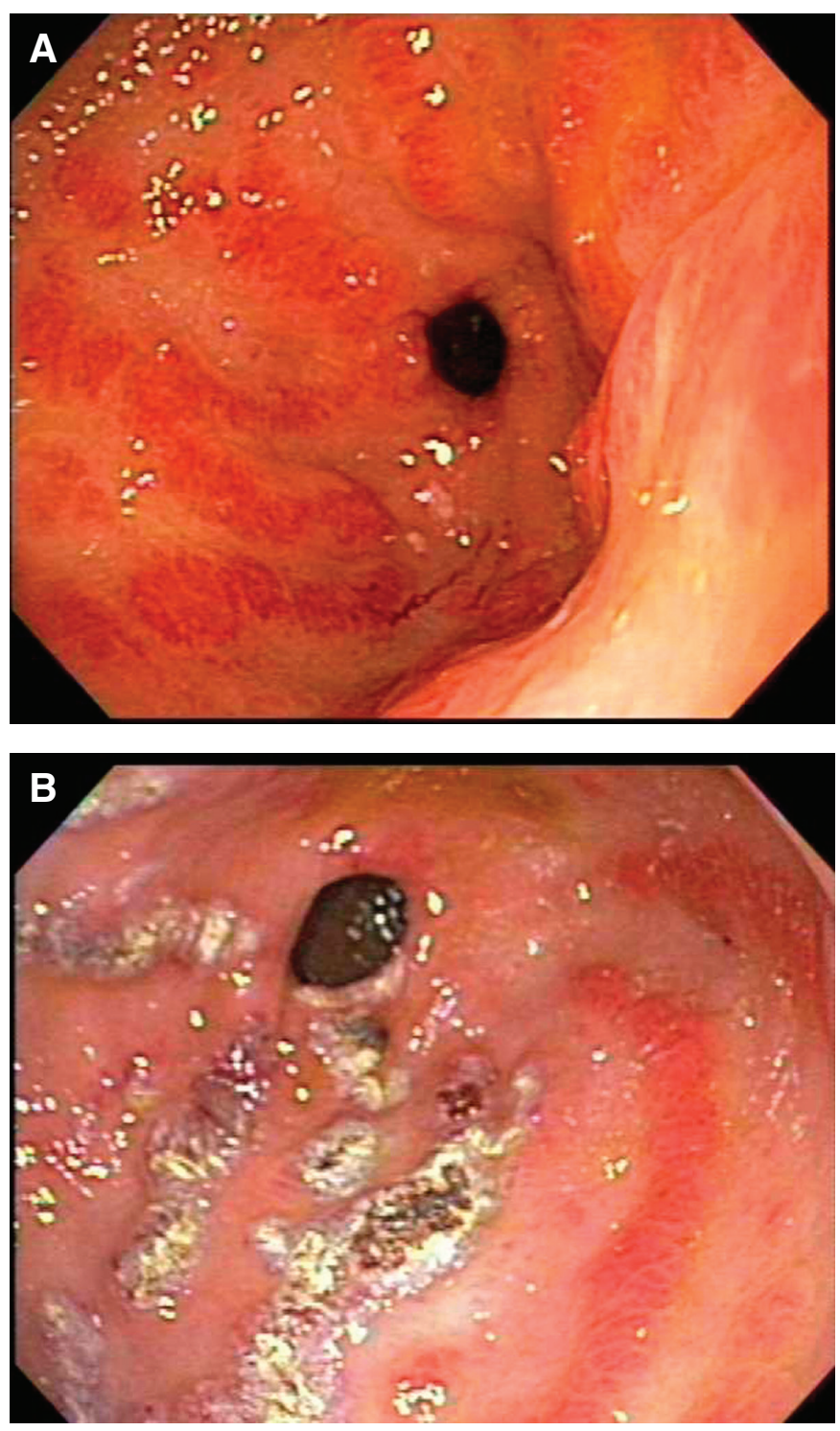

Figure 2. Endoscopy from case 2 (A) showing the striped watermelon appearance of gastric antral vascular ectasia and (B) after treatment with Argon plasma coagulation. 

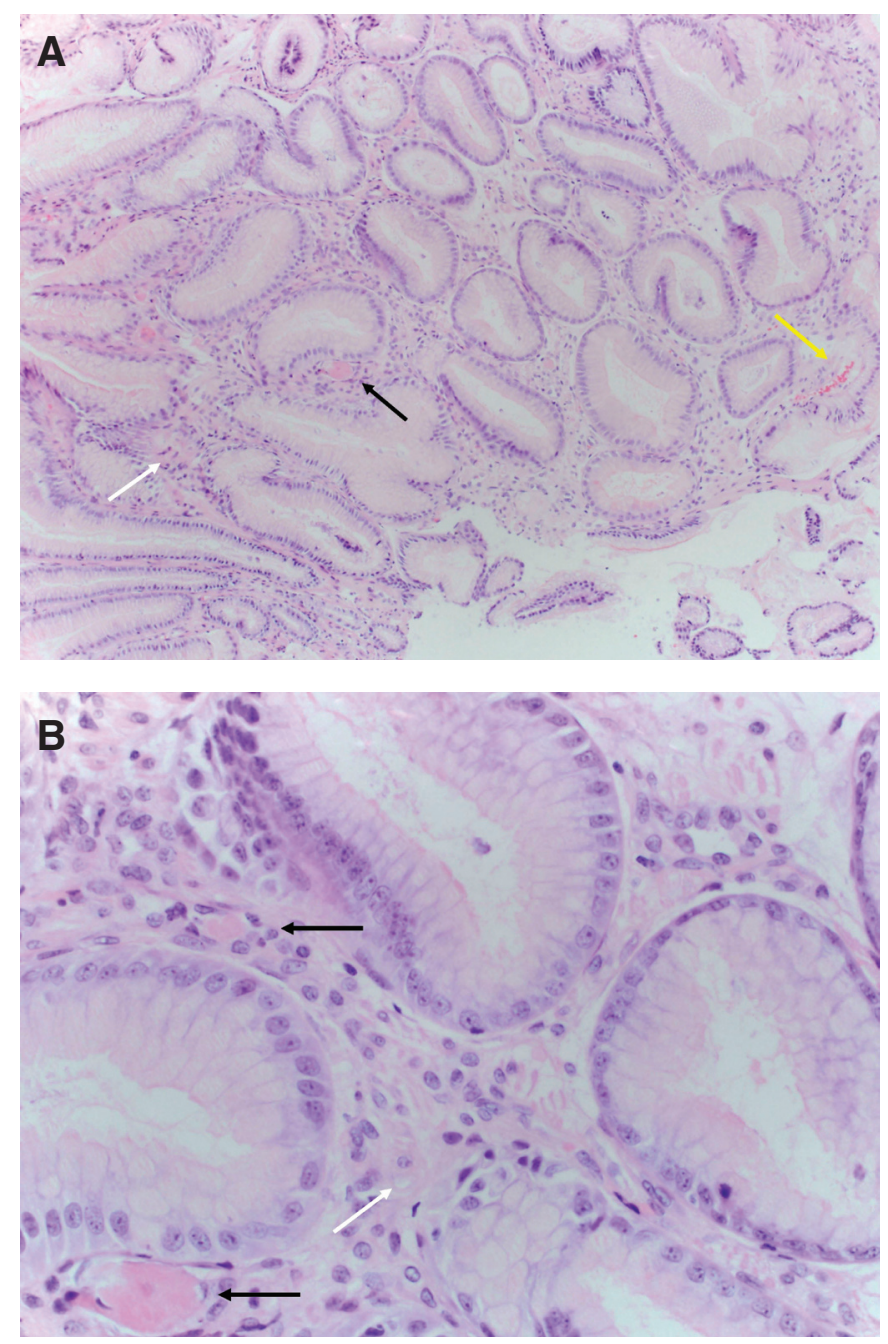

Figure 3. Gastric antral biopsy from case 2 showing features characteristic of gastric antral vascular ectasia (GAVE). (A) Fibromuscular proliferation within the lamina propria (white arrow) with capillary fibrin thrombosis (black arrow) and vascular congestion (yellow arrow) (hematoxylin and eosin, intermediate magnification). (B) Fibromuscular proliferation within the lamina propria (white arrow) and two capillaries harboring fibrin thrombi (black arrows) (hematoxylin and eosin, high magnification).

Over an 18-month follow-up period, the patient was treated with four sessions of APC. She required a blood transfusion for severe anemia on two occasions. After being placed on iron supplementation, her hemoglobin level increased from $8.6 \mathrm{gm} / \mathrm{dL}$ to $10.5 \mathrm{gm} / \mathrm{dL}$, and there has been a significant reduction in transfusion dependence.

\section{Discussion}

The first report of GAVE in the literature in 1953 was by Rider et $\mathrm{al}^{2}$, who described the condition in an elderly female patient with chronic iron deficiency anemia. An antrectomy specimen revealed "erosive atrophic gastritis with marked veno-capillary ectasia." ${ }^{2}$ In 1984, Jabbari et $\mathrm{al}^{3}$ described the characteristic endoscopic findings of "longitudinal antral folds ... converging on the pylorus." The endoscopic appearance resembled the stripes on a watermelon, and they coined the term "watermelon stomach."

Generally, GAVE is associated with underlying chronic illness. Cirrhosis of the liver has been found in $30 \%$ of cases. ${ }^{4}$ Among patients without cirrhosis, GAVE is usually associated with underlying autoimmune conditions. ${ }^{5}$ Gostout et $\mathrm{al}^{5}$ reported that $62 \%$ of patients had coexistent autoimmune connective tissue disorder, particularly Raynaud's phenomenon, which is noted in $31 \%$ of patients with GAVE. Other underlying conditions include systemic sclerosis and CREST syndrome (calcinosis, Raynaud's syndrome, esophageal dysmotility, sclerodactyly, and telangiectasia)..$^{4-7}$ There have been published case reports of GAVE in patients with essential hypertension, ${ }^{8}$ chronic renal failure, ${ }^{8}$ acute myeloid leukemia, ${ }^{9}$ and bone marrow transplant. ${ }^{10}$

In a single-center study of 45 patients with GAVE, $71 \%$ were female, with an average age of 73 years. ${ }^{5}$ In that study, approximately $89 \%$ of patients presented with transfusiondependent anemia. ${ }^{5}$ More recently, two papers have reported two characteristic endoscopic appearances of GAVE with different epidemiological aspects. Cirrhosis is commonly associated with a diffuse appearance of GAVE, involving the whole antrum without interruption; whereas non-cirrhotic patients are more likely to have a typical striped "watermelon" appearance. ${ }^{11,12}$ Our two patients fit these respective endoscopic patterns. Epidemiological differences have been noted in these two groups, and characteristics of the two patterns are listed in table $1.5,11$

The pathophysiology of GAVE remains unclear. Several theories have been proposed, including achlorhydria, hypergastrinemia, and low pepsinogen levels. The pathogenesis of the histologic changes, most notably the lamina propria fibromuscular proliferation and vascular dilatation with thrombosis, is unclear. Increased levels of hormones with vasodilating properties, such as gastrin and prostaglandin $\mathrm{E}_{2}$, have been observed in patients with GAVE, and it has been suggested that failure of liver processing functions may lead to a build-up of these hormones, contributing to the pathogenesis of GAVE. ${ }^{13}$

Several studies have suggested the mechanical stress theory in the pathogenesis of GAVE. Charneua et $\mathrm{al}^{14}$ found that antral motility time was significantly increased in patients with GAVE when compared to healthy controls. Quintero et a ${ }^{15}$ postulated that peristaltic waves of loosely attached antral mucosa draw the mucosa in longitudinal folds and induce fibromuscular proliferation and secondary formation of ectatic vessels. Fibromuscular proliferation and capillary ectasia with microvascular thrombosis of the lamina propria form the histological hallmark of GAVE; the theory of mechanical stress is therefore strengthened by the histological findings in GAVE. . $^{10,16-18}$

Due to the increasing use of endoscopy and increased awareness of the condition, GAVE is now more frequently 
Table 1. Epidemiological differences in the two subsets of gastric antral vascular ectasia.

\begin{tabular}{lll}
\hline & Punctate (case 1) & Classic (case 2) \\
\hline Underlying Conditions & Cirrhosis & Autoimmune disease, hypertension, diabetes \\
Mean age (years) & 65 & 73 \\
Gender predilection & Male $(\mathrm{M}: \mathrm{F}=3: 1)$ & Female (M:F = 1:3) \\
Endoscopy & Diffuse punctate & Striped (watermelon) \\
Mean hemoglobin (gm/dL) & 10.2 & 7.2 \\
Clinical presentation & Acute bleeding & Occult bleeding \\
\hline
\end{tabular}

diagnosed. ${ }^{18}$ It is important that GAVE be distinguished from portal hypertensive gastropathy (PHG) and antral gastritis, especially in patients with portal hypertension. Patients with GAVE have more advanced cirrhosis (by Child-Pugh scoring), lower serum gastrin, and greater blood loss than patients with PHG. ${ }^{19,20}$ While PHG can be controlled through the use of medications to relieve portal hypertension, endoscopic intervention remains the mainstay of therapy for GAVE.

Endoscopically, PHG is typically more predominant in the fundus and the body of the stomach, whereas GAVE mainly involves the antrum. ${ }^{9,19}$ However, severe PHG can occur in the antrum and resemble GAVE. ${ }^{21}$ It is unclear as to whether GAVE may involve the proximal stomach. In two separate published case series, the patient numbers were small, and neither documented the presence of thrombi at the proximal stomach; therefore, it is possible that some patients had coexistent GAVE and PHG. ${ }^{22,23}$ The role of biopsies becomes important, since microscopically, GAVE demonstrates more prominent vascular ectasia, fibrin thrombosis $(P=0.006)$, and fibromuscular proliferation/fibrohyalinosis than PHG. ${ }^{19}$

Treatment of GAVE includes initial resuscitation and symptomatic therapy with intravenous fluids and blood products. ${ }^{17}$ Medical therapy aimed at reducing portal pressures has had limited success in the treatment of GAVE. ${ }^{16}$ Corticosteroids have been used in patients to treat GAVE; in a case series of eleven patients treated with oral steroids, six had complete resolution of bleeding over a mean follow-up period of three years. ${ }^{24,25}$

There have been a few reports where control of bleeding was achieved with estrogen and progesterone. ${ }^{26,27}$ The rationale for hormonal therapy was the observation that epistaxis due to Osler-Weber-Rendu syndrome decreased during pregnancy. In a study involving six patients with GAVE, Tran et al ${ }^{26}$ documented cessation of bleeding and reduction in transfusion requirements in patients treated with ethinyl estradiol with no change in endoscopic appearance. There have also been reports of using tranexamic acid in the treatment of GAVE, with reduction in bleeding and transfusion requirements. ${ }^{28}$

The mainstay of therapy remains endoscopic. ${ }^{13,17,18,29,30}$ Neodymium:yttrium-aluminum-garnet (Nd:YAG) laser has been widely used in the treatment of GAVE. ${ }^{17,29}$ In one study,
13 transfusion-dependent patients were treated with Nd:YAG laser, of whom 12 had remarkable response with elimination of transfusion requirement over a median follow-up of two years. ${ }^{8,31}$ Argon plasma coagulation (APC) has been found to be equally effective in the treatment of GAVE and superior in cost, convenience, and complication rates. ${ }^{29}$ APC is a noncontact electro-coagulation technique using a jet of ionized argon gas to deliver monopolar current to the target tissues. ${ }^{32}$ In a study of 26 patients treated with APC, transfusion requirement elimination was seen in $77 \%$ over a mean follow-up of 16 months. ${ }^{33}$ The benefit of APC lies in the consideration that the depth of penetration can be easily controlled, thus avoiding excessive blood loss. We used this modality in both of our patients, with significant improvement in bleeding. Multiple sessions may be required to reduce future episodes and/or decrease transfusion dependence, as has been noted in our second patient.

Recently, Wells et $\mathrm{al}^{34}$ reported a study demonstrating the superiority of endoscopic band ligation in the treatment of GAVE when compared to endoscopic thermal therapy. Endoscopic band ligation is the current standard of care for variceal ligation. In patients with GAVE, endoscopic band ligation resulted in increased hemoglobin levels and decreased blood transfusions and hospital admissions compared to endoscopic thermal therapy. Additionally, fewer treatment sessions were necessary, likely due to the ability of endoscopic band ligation to treat a larger area of the mucosa at once. No randomized, prospective studies have been performed to conclusively demonstrate the superiority of endoscopic band ligation over conventional therapies, but it offers a promising new therapeutic option. ${ }^{34}$

Before the advent of endoscopic therapy, GAVE was commonly treated by antrectomy. ${ }^{3,17,18}$ However, surgical resection is often associated with significant morbidity and mortality and should be reserved for patients who do not respond to medical or endoscopic treatment.

Gross et $\mathrm{al}^{35}$ reported results of their pilot study that used radiofrequency ablation (the $\mathrm{HALO}^{90}$ system, BÂRRX Medical, Inc, Sunnyvale, CA) for the treatment of GAVE in six patients. All six patients responded favorably with improved post-procedure hemoglobin levels and a decrease in transfusion requirement with no significant complications. 
Endoscopic ablation has been found to be effective in Barrett esophagus; however, it has not been well-studied in vascular ectasia. It may be another tool in the treatment of GAVE.

\section{Conclusion}

GAVE is a rare cause of upper gastrointestinal bleeding, presenting with symptoms ranging from occult bleeding to acute blood loss requiring resuscitation. The etiology of GAVE is unknown, and the associated comorbidities of patients with GAVE are varied, including cirrhosis and several autoimmune disorders. The cases presented here demonstrate the two different appearances of GAVE in patients with distinct underlying conditions and underscore the importance of correct diagnosis. Patients with cirrhosis may have a diffuse punctate appearance of the antrum on endoscopy in contrast to the typical striped watermelon appearance seen in association with other conditions. It is important to distinguish this entity from PHG and antral gastritis, as the management is different. Argon plasma coagulation has been employed successfully in the treatment of GAVE, as in the cases presented here, though multiple sessions may be required. Several other endoscopic interventions are available, and surgical antrectomy is generally considered as a last resort. Juxtaposition of these two cases illustrates the two strikingly different presentations, etiologies, and endoscopic appearances of GAVE.

\section{Acknowledgements}

The authors thank the Marshfield Clinic Research Foundation's Office of Scientific Writing and Publication for editorial assistance in the preparation of this manuscript.

\section{References}

1. Dulai GS, Jensen DM, Kovacs TO, Grainek IM, Jutabha R. Endoscopic treatment outcomes in watermelon stomach patients with and without portal hypertension. Endoscopy 2004;36:68-72.

2. Rider JA, Klotz AP, Kirsner JB. Gastritis with veno-capillary ectasia as a source of massive gastric hemorrhage. Gastroenterology 1953;24:118-123.

3. Jabbari M, Cherry R, Lough JO, Daly DS, Kinnear DG, Goresky CA. Gastric antral vascular ectasia: the watermelon stomach. Gastroenterology 1984;87:1165-1170.

4. Ward EM, Raimondo M, Rosser BG, Wallace MB, Dickson RD. Prevalence and natural history of gastric antral vascular ectasia in patients undergoing orthotopic liver transplantation. J Clin Gastroenterol 2004;38:898-900.

5. Gostout CJ, Viggiano TR, Ahlquist DA, Wang KK. Larson MV, Balm R. The clinical and endoscopic spectrum of the watermelon stomach. J Clin Gastroenterol 1992;15:256-263.

6. Beales IL. Watermelon stomach in the CREST syndrome. Postgrad Med J 1994;70:766-767.

7. Watson M, Hally RJ, McCue PA, Varga J, Jiménez SA. Gastric antral vascular ectasia (watermelon stomach) in patients with systemic sclerosis. Arthritis Rheum 1996;39:341-346.

8. Liberski SM, McGarrity TJ, Hartle RJ, Varano V, Reynolds D. The watermelon stomach: long-term outcome in patients treated with Nd:YAG laser therapy. Gastrointest Endosc 1994;40:584-587.
9. Takahashi T, Miya T, Oki M, Sugawara N, Yoshimoto M, Tsujisaki M. Severe hemorrhage from gastric vascular ectasia developed in a patient with AML. Int J Hematol 2006;83:467-468.

10. Tobin RW, Hackman RC, Kimmey MB, Durtschi MB, Hayashi A, Malik R, McDonald MF, McDonald GB. Bleeding from gastric antral vascular ectasia in marrow transplant patients. Gastrointest Endosc 1996;44:223-229.

11. Ito M, Uchida Y, Kamano S, Kawabata H, Nishioka M. Clinical comparisons between two subsets of gastric antral vascular ectasia. Gastrointest Endosc 2001;53:764-770.

12. Chaves DM, Sakai P, Oliveira CV, Cheng S, Ishioka S. Watermelon stomach: clinical aspects and treatment with argon plasma coagulation. Arq Gastroenterol 2006;43:191-195.

13. Ripoll C, Garcia-Tsao G. The management of portal hypertensive gastropathy and gastric antral vascular ectasia. Digest Liv Dis 2011;43:345-351.

14. Charneau J, Petit R, Calès P, Dauver A, Boyer J. Antral motility in patients with cirrhosis with or without gastric antral vascular ectasia. Gut 1995;37:488-492.

15. Quintero E, Pique JM, Bombi JA, Bordas JM, Sentis J, Elena M, Bosch J, Rodes J. Gastric mucosal vascular ectasias causing bleeding in cirrhosis. A distinct entity associated with hypergastrinemia and low serum levels of pepsinogen I. Gastroenterology 1987;93:1054-1061.

16. Selinger CP, Ang YS. Gastric antral vascular ectasia (GAVE): an update on clinical presentation, pathophysiology and treatment. Digestion 2008;77:131-137.

17. Novitsky YW, Kercher KW, Czerniach DR, Litwin DE. Watermelon stomach: pathophysiology, diagnosis, and management. J Gastrointest Surg 2003;7:652-661.

18. Sebastian S, O’Morain CA, Buckley MJ. Review article: current therapeutic options for gastric antral vascular ectasia. Aliment Pharmacol Ther 2003;18:157-165.

19. Burak KW, Lee SS, Beck PL. Portal hypertensive gastropathy and gastric antral vascular ectasia (GAVE) syndrome. Gut 2001;49:866-872.

20. Payen JL, Cales P, Voigt JJ, Barbe S, Pilette C, Dubuisson L, Desmorat H, Vinel JP, Kervran A, Chayvialle JA, et al. Severe portal hypertensive gastropathy and antral vascular ectasia are distinct entities in patients with cirrhosis. Gastroenterology 1995;108:138-144.

21. Thuluvath PJ, Yoo HY. Portal hypertensive gastropathy. Am J Gastroenterol 2002;97:2973-2978.

22. Stotzer PO, Willén R, Kilander AF. Watermelon stomach: not only an antral disease. Gastrointest Endosc. 2002; 55:897-900.

23. Al-Haddad M, Ward EM, DeVault KR, Bouras EP, Raimondo M. Vascular ectasia of the proximal stomach. Dig Dis Sci. 2007;52:1367-1369.

24. Bhowmick BK. Watermelon stomach treated with oral corticosteroid. J R Soc Med 1993;86:52.

25. Calam J, Walker RJ. Antral vascular lesion, achlorhydria, and chronic gastrointestinal blood loss: response to steroids. Dig Dis Sci 1980;25:236-239.

26. Tran A, Villeneuve JP, Bilodeau M, Willems B, Marleau D, Fenyves D, Parent R, Pomier-Layrargues G. Treatment of chronic bleeding from gastric antral vascular ectasia (GAVE) with estrogen-progesterone in cirrhotic patients: an open pilot study. Am J Gastroenterol 1999;94:2909-2911.

27. Manning RJ. Estrogen/progesterone treatment of diffuse antral vascular ectasia. Am J Gastroenterol 1995;90:154-156.

28. Khan S, Vaishnavi A. Pharmacotherapy for gastric antral vascular ectasia: dramatic response to tranexamic acid. Gastrointest Endosc 2009;70:191-192.

29. Rosenfeld G, Enns R. Argon photocoagulation in the treatment of gastric antral vascular ectasia and radiation proctitis. Curr Endoscop Prac 2009;23:801-804. 
30. Ripoll C, Garcia-Tsao G. Management of gastropathy and gastric vascular ectasia in portal hypertension. Clin Liver Dis 2010;14:281-295.

31. Gostout CJ, Ahlquist DA, Radford CM, Viggiano TR, Bowyer BA, Balm RK. Endoscopic laser therapy for watermelon stomach. Gastroenterology 1989;96:1462-1465.

32. Dumot JA, Greenwald BD. Argon plasma coagulation, bipolar cautery, and cryotherapy: ABC's of ablative techniques. Endoscopy 2008;40:1026-1032.

33. Kwan V, Bourke MJ, Williams SJ, Gillespie PE, Murray MA, Kaffes AJ, Henriquez MS, Chan RO. Argon plasma coagulation in the management of symptomatic gastrointestinal vascular lesions: experience in 100 consecutive patients with long-term follow-up. Am J Gastroenterol 2006;101:58-63.

34. Wells CD, Harrison ME, Gurudu SR, Crowell MD, Byrne TJ, Depetris G, Sharma VK. Treatment of gastric antral vascular ectasia (watermelon stomach) with endoscopic band ligation. Gastrointest Endosc 2008;68:231-236.

35. Gross SA, Al-Haddad M, Gill KR, Schore AN, Wallace MB. Endoscopic mucosal ablation for the treatment of gastric antral vascular ectasia with the HALO90 system: a pilot study. Gastrointest Endosc 2008;67:324-327.

\section{Author Affiliations}

Papia Kar, MD*; Subhashis Mitra, MD*; Jeffrey M. Resnick, $M D^{*}$; Camille F. Torbey, MD, FACP, AGAF*

*Department of Internal Medicine, Marshfield Clinic, Marshfield, Wisconsin USA

${ }^{\dagger}$ Lab-Pathology, Marshfield Clinic, Marshfield, Wisconsin USA

Department of Gastroenterology, Marshfield Clinic, Marshfield, Wisconsin USA 